\title{
Repair of recoarctation after the Norwood operation: The right-sided posterior approach
} \author{
Canada \\ From the Department of Surgery, University of Alberta, Edmonton, Alberta, Canada. \\ Disclosures: Authors have nothing to disclose with regard to commercial support. \\ Received for publication April 10, 2016; revisions received June 3, 2016; accepted for publication June 19, 2016; \\ available ahead of print July 25, 2016 \\ Address for reprints: Ivan M. Rebeyka, MD, University of Alberta Hospital, 8440112 St NW, Edmonton, Alberta \\ T6G 2B7, Canada (E-mail: ivan.rebeyka@ahs.ca). \\ J Thorac Cardiovasc Surg 2016;152:1622-4 \\ $0022-5223 / \$ 36.00$ \\ Copyright (C) 2016 by The American Association for Thoracic Surgery \\ http://dx.doi.org/10.1016/j.jtcvs.2016.06.035
}

Billie-Jean Martin, MD, PhD, Michiko Maruyama, MD, and Ivan M. Rebeyka, MD, Edmonton, Alberta,

Despite dramatic improvements in outcomes after neonatal aortic arch reconstruction, recurrent aortic coarctation remains an unfortunately common complication. Nearly onefifth of patients undergoing a Norwood operation eventually require either surgical or catheter intervention for coarctation, generally before or coincident with second-stage palliation. ${ }^{1}$

Since 2005, all neoaortic arch reconstructions done at the time of the Norwood operation at the University of Alberta Hospital have been done with glutaraldehyde-treated pulmonary homograft, with small changes in surgical technique over time. ${ }^{2,3}$ Rates of recoarctation are similar to those published by other authors. To facilitate repair of recoarctation, we have developed a new surgical technique of approaching the distal aortic arch medially, or from the right side.

\section{TECHNIQUE}

Patients were selected for aortic arch repair according to data from both clinical examination and multiple imaging modalities. Most arch repairs were done simultaneously with another procedure, frequently a bidirectional cavopulmonary shunt. All procedures were done through a median sternotomy.

Before initiation of cardiopulmonary bypass, the aortic arch, neck vessels, and superior vena cava were mobilized, and tourniquets were placed around the arch vessels. The distal ascending aorta was cannulated with a straight DLP cannula (Medtronic, Inc, Minneapolis, Minn) and the right atrium with a venous cannula, and patients were cooled to $22^{\circ} \mathrm{C}$ (Figure 1, A). After 20 minutes of cooling, the aorta was clamped and cardioplegia was administered in the neoaortic root. The aortic cannula was repositioned into the innominate artery, the arch vessels were snared, and pump flow was reduced to $50 \mathrm{~mL} / \mathrm{kg} / \mathrm{min}$. Cerebral saturations were monitored throughout with near-infrared spectroscopy monitors.

During cooling, the right side of the aorta was exposed by mobilizing the arch back to the isthmus. The recurrent laryngeal nerve was identified and preserved during dissection. The trachea was left undisturbed, with dissection in the

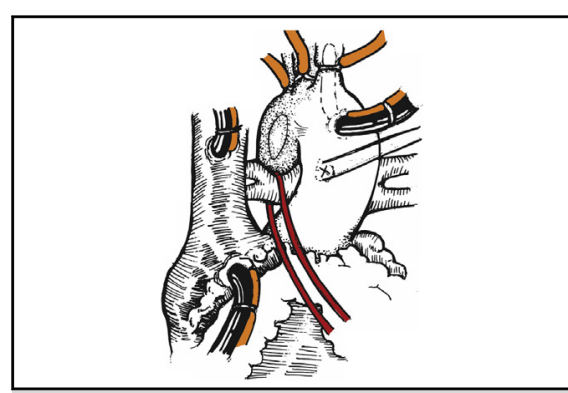

Right-sided posterior approach to exposure and repair of recurrent aortic coarctation.

Central Message

Recurrent aortic coarctation is an unfortunately common early complication after the Norwood operation. We present an alternate approach to

See Editorial Commentary page 1624. surgical repair of this lesion.

plane immediately adjacent to the aorta. The superior vena cava was retracted laterally, and the right pulmonary artery was mobilized with a vessel loop and retracted inferiorly. This allowed excellent visualization of the distal aortic arch and proximal descending aorta (Figure 1, B). With the pump flow reduced, the stenotic area was incised parallel to the line of the aorta, and a pump sucker was placed in the descending aorta. A patch of bovine pericardium slightly larger in width than the diameter of the unobstructed descending aorta was prepared. The distal end was trimmed, and the patch was sutured in place (Figure 1, $C$, and Figure 2, A). With the suture line complete, snares were removed from the head vessels, the aortic cannula was repositioned into the aorta, and full cardiopulmonary bypass was recommenced. Initial assessment of the repair included confirmation that the area of repair distended well without any leak (Figure 2, B). The patients were rewarmed, and any additional planned procedures were performed.

Since 2010, all subjects requiring repeated arch intervention after neonatal arch repair have undergone repair with this strategy. No patients had residual obstruction on intraoperative echocardiography. No patients had postoperative clinical evidence of recurrent laryngeal nerve dysfunction. All patients underwent postoperative echocardiography as well, as late as 5 years after surgery, again demonstrating no significant recoarctation. 


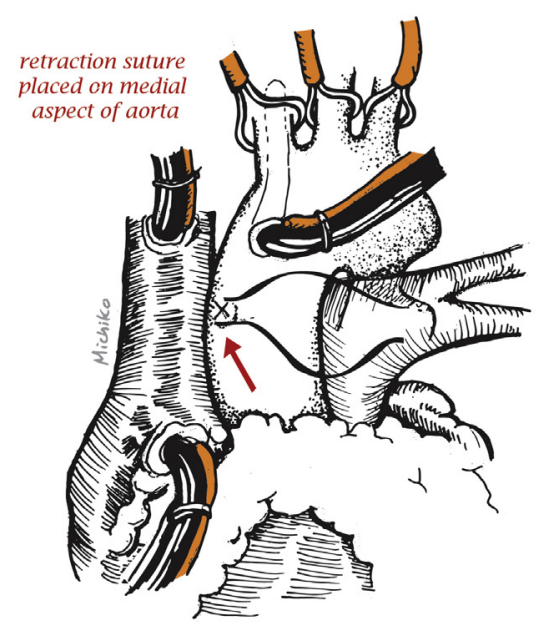

A

FIGURE 1. A, Initial cannulation and exposure prior to mobilization. The distal ascending aorta, superior vena cava, and right atrium are each cannulated In patients not requiring a bidirectional cavopulmonary connection, single right atrial cannulation is used. Each of the head and neck vessels are encircled and then snared before the aorta is opened. The aortic cannula is advanced into the innominate artery for antegrade cerebral perfusion. B, View of distal arch after mobilization. The aorta is retracted to the left, and the right pulmonary artery is retracted inferiorly. C, Appearance of the aorta after repair.

\section{DISCUSSION}

Recurrent aortic coarctation after neonatal arch repair represents a surgical challenge. Although many different strategies have been used to reduce its occurrence, it continues to occur in a significant percentage of patients. Leaving patients with a residual arch gradient results in worsening ventricular function and increasing atrioventricular valvular regurgitation in patients with single-ventricle physiology or progressive left ventricular hypertrophy in those with biventricular repairs. Accessing the distal aorta is more difficult at the time of reoperation than at the original arch reconstruction as a result of adhesions, tissue calcification, and somatic growth. Other authors have described various methods of repair, ${ }^{4}$ including repeated median sternotomy with access to the aorta from the left side and approaching the aorta through a left thoracotomy. We do not find that the left- sided approach allows visualization as good as that obtained from the right, and there may be concerns about distal perfusion in large children with an off-pump thoracotomy approach. We have found that approaching the aorta from the right (medial) side facilitates repair by improving visualization and access to the aortic isthmus, and because relatively new planes are exposed during dissection, avoiding adhesions. In addition to using this strategy for patients after the Norwood procedure, we have also used it after arterial switch and coarctation repair, where mobilizing the pulmonary arteries to visualize the distal arch can be difficult, as well as for 1 child after interrupted aortic arch surgery. Although in general the children have been smaller than $10 \mathrm{~kg}$ at the time of reoperation, the approach was used for 1 child who weighed $20 \mathrm{~kg}$. Thus far, this approach has been used for a dozen children, with only 1 returning for a
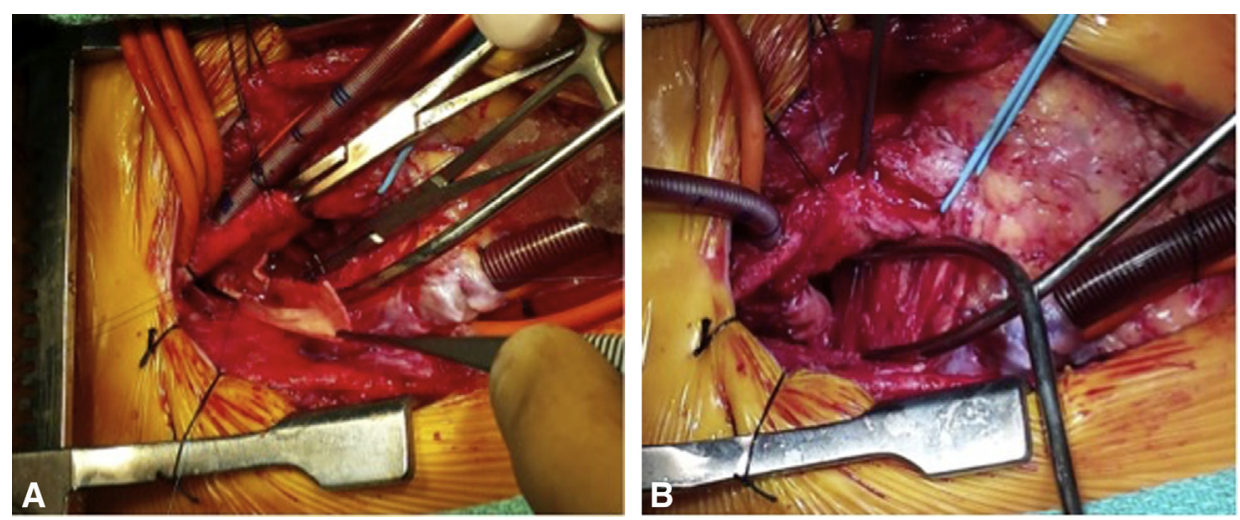

FIGURE 2. Intraoperative images show the appearance of the aorta with the patch partially sewn in, demonstrating excellent exposure (A), and the final appearance of the patch with the aorta distended fully (B). 
repeated aortic intervention at a more proximal arch location. The right-sided approach to the aortic arch provides excellent exposure and facilitates repair of recurrent obstruction.

\section{References}

1. Hill KD, Rhodes JF, Aiyagari R, Baker GH, Bergersen L, Chai PJ, et al. Intervention for recoarctation in the single ventricle reconstruction trial: incidence, risk, and outcomes. Circulation. 2013;128:954-61.
2. Laing BJ, Ross DB, Meyer SR, Campbell P, Halpin AM, West LJ, et al. Glutaraldehyde treatment of allograft tissue decreases allosensitization after the Norwood procedure. J Thorac Cardiovasc Surg. 2010;139:1402-8.

3. Meyer SR, Campbell PM, Rutledge JM, Halpin AM, Hawkins LE, Lakey JR, et al. Use of an allograft patch in repair of hypoplastic left heart syndrome may complicate future transplantation. Eur J Cardiothorac Surg. 2005;27: 554-60.

4. Mery CM, Fraser CD. Anatomic repair of recurrent aortic arch obstruction. Oper Tech Thorac Cardiovasc Surg. 2012;17:271-9.

\title{
EDITORIAL COMMENTARY
}

\section{The "right" way to repair recoarctation after the Norwood operation}

\author{
Harold M. Burkhart, MD, and Jess L. Thompson, MD
}

\footnotetext{
From the Division of Cardiovascular and Thoracic Surgery, University of Oklahoma Health Sciences Center, Oklahoma City, Okla.

Disclosures: Authors have nothing to disclose with regard to commercial support.

Received for publication Aug 8, 2016; accepted for publication Aug 8, 2016; available ahead of print Sept 15, 2016.

Address for reprints: Harold M. Burkhart, MD, Division of Cardiovascular and Thoracic Surgery, University of Oklahoma Health Sciences Center, PO Box 26901, WP-2230, Oklahoma City, OK 73105 (E-mail: Harold-burkhart@ouhsc.edu).

J Thorac Cardiovasc Surg 2016;152:1624-5

$0022-5223 / \$ 36.00$

Copyright (C) 2016 by The American Association for Thoracic Surgery

http://dx.doi.org/10.1016/j.jtcvs.2016.08.009
}

Residual lesions after Norwood stage I palliation for hypoplastic left heart syndrome are associated with poor outcomes. Aortic arch obstruction or recoarctation may result in depressed right ventricular function or increased atrioventricular valve regurgitation, putting the patient at an increased risk of death. The frequency of recurrent coarctation after Norwood reconstruction is significant, with the Single Ventricle Reconstruction trial reporting an incidence of $18 \%$ in a group of 549 patients. ${ }^{1}$ In that trial, 97 patients with recoarctation underwent a total of 131 aortic interventions ( 92 by balloon aortoplasty and 39 surgically), with $39 \%$ of the patients undergoing balloon aortoplasty needing another aortic intervention. At evaluation before stage II of Norwood palliation, patients with recoarctation had higher pulmonary arterial pressures, higher pulmonary vascular resistance, and increased heart volumes, as measured echocardiographically.

Surgical data have been presented reporting a decreased incidence of recurrent coarctation after a modification of Norwood stage I palliation., 2 The techniques involve complete mobilization of the aortic arch, head vessels, and proximal descending aorta to limit tension. The

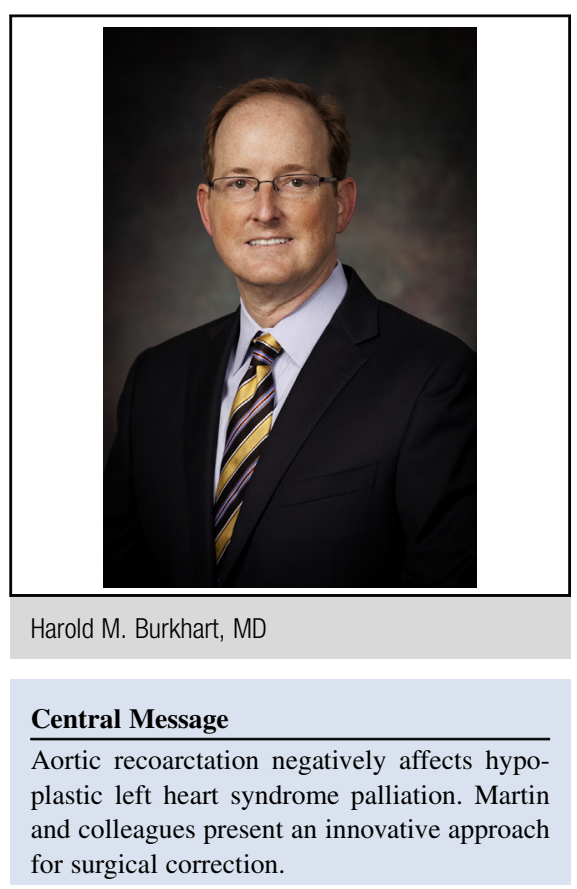

See Article page 1622

coarctation and ductal tissue are completely excised. The proximal descending aorta is then spatulated both anteriorly and posteriorly (interdigitating technique) in the hope of decreasing the rate of recoarctation. When recurrent coarctation does occur, it is treated either with balloon aortoplasty for more discrete lesions or with surgical intervention for complex recoarctations and lesions not responsive to catheter-based procedures. The 